\title{
Update on Antihistamine Treatment for Chronic Urticaria in Children
}

\section{Anna Belloni Fortina, MD* Elena Fontana, MD}

\author{
Address \\ *Pediatric Dermatology Unit, Department of Medicine, University of Padua, \\ Clinica Dermatologica, Via C. Battisti, 206, 35128 Padova, Italy \\ Email: belloni@pediatria.unipd.it
}

Published online: 18 May 2014

(C) Springer International Publishing AG 2014

Keywords Chronic urticaria - Children - Therapy - Antihistamines - Drugs - Bilastine - Cetirizine - Desloratadine . Ebastine - Fexofenadine $\cdot$ Levocetirizine $\cdot$ Loratadine - Mizolastine - Rupatadine - Steroids - Montelukast •

Phototherapy · Dapsone - Cyclosporine A · Omalizumab

\section{Opinion statement}

Urticaria is a heterogeneous group of diseases, which may have different causes and mechanisms but share similar clinical features. It is clinically defined by the presence of wheals and/or angioedema. The diagnosis of urticaria is based on the evaluation of clinical manifestations. Urticaria is conventionally classified as acute or chronic. Chronic urticaria (CU) has been defined as daily or nearly daily occurrence of wheals and/or angioedema lasting longer than 6 weeks. Very little is known of the epidemiology of urticaria in infants and children, and still less is known of the prevalence of CU. The prevalence of $\mathrm{CU}$ in children is reported to vary between 0.1 and $0.3 \%$. The natural history of CU in children tends toward spontaneous resolution: approximately $25 \%$ of patients go into remission within 3 years. Many etiological factors have been associated with CU, but most cases remain idiopathic despite exhaustive investigations. Among the non-idiopathic CU cases, the most common etiologies are autoimmune origin, followed by physical triggers. Food allergy and intolerance, as well as infections, are other less frequent possible causes. However, well-controlled studies to support the different etiologies and/or associations are lacking. The management of childhood CU includes identification and elimination of the triggering factors and symptomatic pharmacological treatment when symptoms appear. The first-line symptomatic therapy is second-generation $\mathrm{H1}$-antihistamines, with dose adjustment for pediatric use. Only a few H1-antihistamines have been investigated for safety in children: cetirizine, levocetirizine, loratadine, fexofenadine, desloratadine, and rupatadine; of these, cetirizine and levocetirizine are the ones that have been most thoroughly investigated for long-term safety and efficacy in children ranging from 6 months to 12 years of age. 
Corticosteroids and other immunosuppressive drugs (e.g., cyclosporine A, dapsone, and omalizumab) should be restricted to very refractory CU cases and used only for a very short period.

\section{Introduction}

Urticaria is a heterogeneous group of diseases, which may have different causes and mechanisms but share similar clinical features. It is clinically defined by the presence of wheals and/or angioedema. A wheal comprises a central swelling, nearly always surrounded by erythema, which usually disappears within $1-24 \mathrm{~h}$ and is associated with pruritus or a burning sensation. Angioedema is characterizing by swelling of the lower dermis, sometimes with pain rather than itching, with frequent involvement beneath mucous membranes, and resolution can take up to $72 \mathrm{~h}[1,2 \bullet \bullet]$.

The diagnosis of urticaria is based on the evaluation of clinical manifestations. Urticaria is conventionally classified as acute or chronic. Chronic urticaria (CU) has been defined as daily or nearly daily occurrence of wheals and/or angioedema lasting longer than 6 weeks $[1,2 \bullet \bullet, 3,4 \bullet \bullet, 5,6 \bullet \bullet]$.

Very little is known of the epidemiology of urticaria in infants and children, and still less is known of the prevalence of $\mathrm{CU}[7 \bullet]$. The prevalence of $\mathrm{CU}$ in children is reported to vary between 0.1 and $0.3 \%$ [8].
The natural history of CU in children tends toward spontaneous resolution: approximately $25 \%$ of patients go into remission within 3 years [8-10].

Many etiological factors have been associated with $\mathrm{CU}$, but most cases remain idiopathic despite exhaustive investigations $[6 \bullet \bullet, 11]$. Among the non-idiopathic CU cases, the most common etiologies are autoimmune origin, followed by physical triggers $[11,12 \bullet \bullet]$.

Food allergy and intolerance, as well as infections, are other less frequent possible causes $[6 \bullet \bullet, 11,12 \bullet \bullet$, $13,14]$. However, well-controlled studies to support the different etiologies and/or associations are lacking.

The management of CU in children includes two main steps $[2 \bullet \bullet, 3,5,6 \bullet \bullet, 12 \bullet \bullet, 15]$ :

- Identification and elimination of the triggering factors through anamnesis and physical examination

- Symptomatic pharmacological treatment when symptoms appear.

\section{Antihistamines as First-Line treatment}

First-line symptomatic therapy is based on the use of systemic H1-antihis-

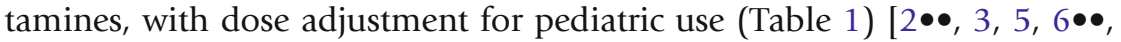
$12 \bullet \bullet, 15]$.

H1-antihistamines work as inverse agonists, which suppress the effects of histamine on its G-protein coupled receptors and lead to a balance displacement between the active and inactive forms of $\mathrm{H} 1$ receptors $[16 \bullet \bullet, 17 \bullet \bullet, 18]$.

$\mathrm{H} 1$-antihistamines are functionally classified into two groups: first-generation and second-generation (new-generation) [19].

First-generation H1-antihistamines have a capacity to cross the bloodbrain barrier and occupy $\mathrm{H} 1$ receptors located on postsynaptic membranes of histaminergic neurons throughout the central nervous system (CNS), thus interfering with histaminergic transmission $[16 \bullet \bullet, 17 \bullet \bullet, 18]$. This means that they frequently cause sedation, drowsiness, and impaired concentration and memory when taken during the day, and poor sleep when taken at night. Furthermore, they have poor receptor selectivity and often interact with re- 


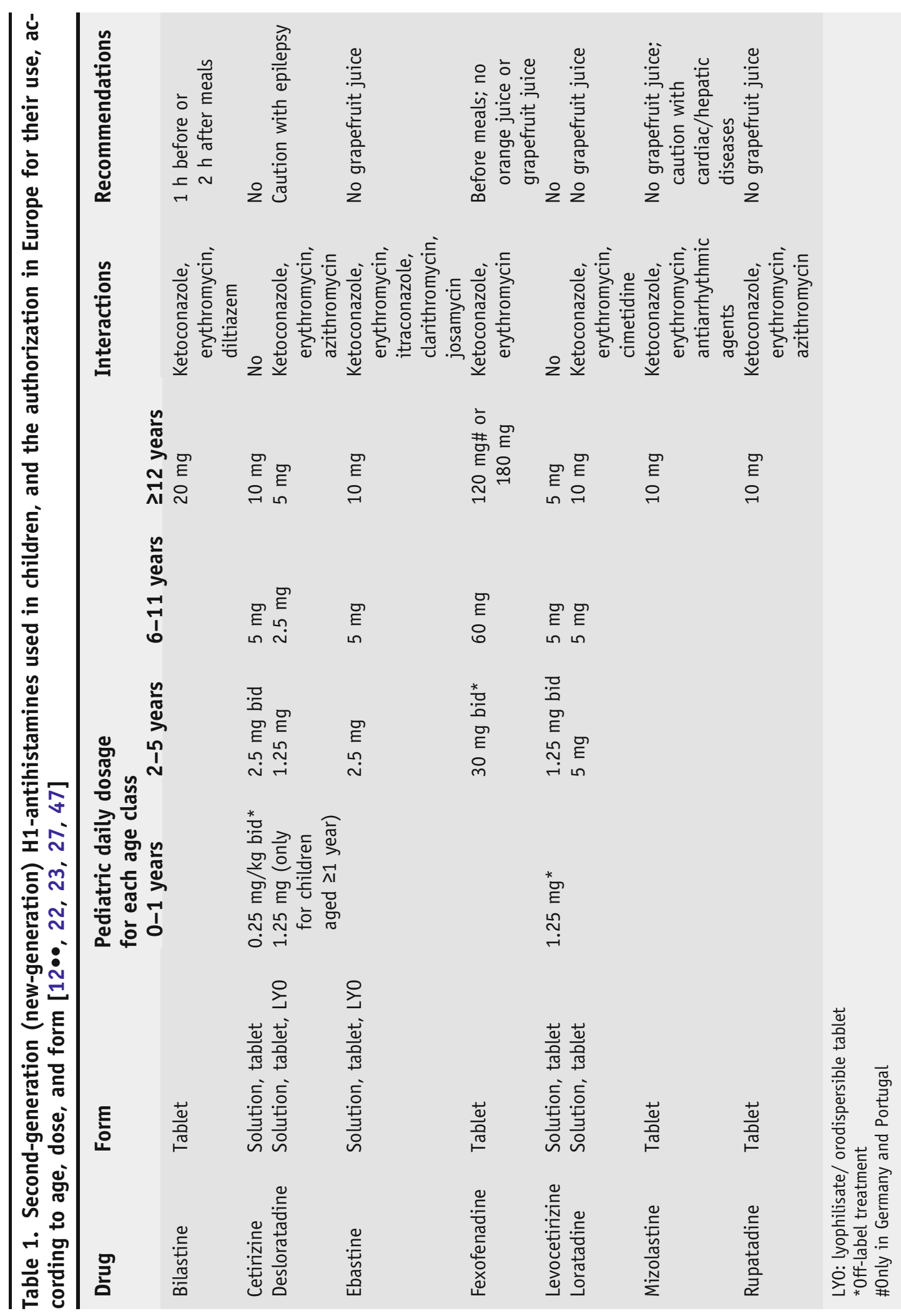


ceptors of other biologically active amines. They may cause many side effects, such as paradoxical excitation, irritability, hyperactivity and hallucinations, constipation, dry mouth, urinary retention, and sinus tachycardia [20].

Second-generation H1-antihistamines (cetirizine, ebastine, loratadine, mizolastine) and new-generation $\mathrm{H} 1$-antihistamines (bilastine,

desloratadine, fexofenadine, levocetirizine, rupatadine) instead have no or only limited penetration of the blood-brain barrier and are much more selective for the histamine $\mathrm{H} 1$ receptor. Thus, they are non-sedating or minimally sedating and have no anticholinergic effects [19].

In clinical practice, both first- and second-generation H1-antihistamines have been usually considered for the treatment of $\mathrm{CU}$ in children.

However, for the reasons explained above, the latest EAACI/GA ${ }^{2} L E N / E D F /$ WAO guidelines recommend that the first-line treatment for urticaria should be second-generation non-sedating H1-antihistamines, and they state that "in patients with urticaria and no special indication, we recommend against the routine use of old sedating first-generation H1-antihistamines" [15].

Up to now, only a few $\mathrm{H} 1$-antihistamines have been investigated for safety in children: cetirizine, levocetirizine, loratadine, fexofenadine, desloratadine, and rupatadine $[4 \bullet \bullet, 12 \bullet \bullet, 19]$; of these, cetirizine and levocetirizine are the ones that have been most thoroughly investigated for long-term safety and efficacy in children ranging from 6 months to 12 years of age $[12 \bullet \bullet, 19]$.

\section{Bilastine (C28H37N303)}

Bilastine belongs to the same piperidine class of antihistamines as loratadine, desloratadine, and fexofenadine. It acts as an $\mathrm{H} 1$ receptor inverse agonist. Its mean oral systemic availability is reported to be $61 \%$. It is recommended that bilastine be administered at least 1 hour before or 2 hours after a meal. Bilastine does not undergo any significant metabolism, and approximately $95 \%$ is excreted in the feces or urine. There is no interaction with cytochrome P450 (CYP) in the liver, and bilastine also does not interact with any other drug, except for ketoconazole, erythromycin, and diltiazem.

Clinical studies of bilastine have shown good tolerability of this drug and have not reported severe adverse effects. The most common adverse effects were headache, somnolence, dizziness, and fatigue. The use of bilastine is approved in Europe for children aged $\geq 12$ years, at the dosage of $20 \mathrm{mg}$ once daily. Studies on its pharmacokinetics, dose response, assessment, efficacy, and adverse effects in children $<12$ years of age are needed [21].

\section{Cetirizine (C21H25CIN203)}

Cetirizine is a metabolic product of hydroxyzine in humans. Cetirizine is a potent and selective antagonist of $\mathrm{H} 1$ receptors. Its plasmatic concentration at steady state is $300 \mathrm{ng} / \mathrm{ml}$, and the peak concentration is reached after $1.0 \pm 0.5$ hours. The absorption of cetirizine is not reduced by food intake; there is no evidence of interaction with alcohol intake. About two thirds of the dose is excreted unchanged in the urine. The terminal half-life of cetirizine is approximately 10 hours. 
Its use is approved in Europe in children $\geq 2$ years old. Clinical studies have shown that cetirizine has minor undesirable effects on the CNS: somnolence, fatigue, dizziness, and headache. In some cases, it has been reported to induce paradoxical CNS stimulation. Although cetirizine is a selective inhibitor of peripheral $\mathrm{H} 1$ receptors and is relatively free of anticholinergic activity, there have been uncommon cases of micturition difficulty, eye accommodation disorders, and dry mouth.

The safety of cetirizine has also been evaluated in children as young as 12 years of age with atopic dermatitis in a randomized, double-blind, placebocontrolled trial lasting 18 months and in a short-term (7-day) investigation in infants (6-12 months of age) $[22,23]$.

\section{Levocetirizine (C21H25CIN203)}

Levocetirizine is the active R-enantiomer of the racemate cetirizine, but it has twice the binding affinity of cetirizine. In children, levocetirizine is rapidly absorbed and reaches its maximum plasma concentration after 1.2 hours. It has a half-life of about 5.7 hours and is minimally metabolized, and its clearance rate is about $0.8 \mathrm{ml} / \mathrm{min} / \mathrm{kg}$. Because of its pharmacokinetics, it has a low potential for drug interactions. Evidence demonstrates that levocetirizine is safe and well tolerated in children. Its use is approved in Europe for children $\geq 2$ years of age [19, 24, 25].

The most common adverse events associated with levocetirizine are upper respiratory tract infections, transient gastroenteritis symptoms, and exacerbation of allergic disease.

The safety of levocetirizine has been evaluated in atopic children aged 1224 months in a randomized, double-blind, placebo-controlled trial lasting 18 months and in a short-term (2-week) investigation in infants aged 612 months and children aged $1-5$ years $[26,27]$.

\section{Loratadine (C22H23CIN202)}

Loratadine is a tricyclic second-generation anti-H1-antihistamine. It undergoes metabolism by hepatic cytochromes. Desloratadine is its main metabolite. It has a half-life of 8 hours and reaches its maximum plasma concentration after about 1.5 hours. It is eliminated via the urine and feces. Substances that act as inhibitors of the CYP3A4 enzyme, such as ketoconazole, erythromycin, cimetidine, and furanocoumarin derivatives (found in grapefruit), lead to increased plasma levels of loratadine [18]. Its use is approved in Europe for children $\geq 2$ years of age [28-30].

\section{Desloratadine (C19H19CIN2)}

Desloratadine is a long-acting tricyclic histamine antagonist with selective H1 receptor histamine antagonist activity. Following oral administration of desloratadine $5 \mathrm{mg}$ once daily, the mean time to the maximum plasma 
concentration was approximately 3 hours. Desloratadine (a major metabolite of loratadine) is extensively metabolized to 3-hydroxydesloratadine, an active metabolite. Desloratadine and 3-hydroxydesloratadine are approximately $82-87 \%$ and $85-89 \%$ bound to plasma proteins, respectively.

The mean plasma elimination half-life of desloratadine is approximately 27 hours.

The most commonly reported adverse reactions are pharyngitis, dry mouth, myalgia, fatigue, somnolence, and dysmenorrhea. In controlled clinical studies, coadministration of desloratadine with ketoconazole, erythromycin, or azithromycin resulted in increased plasma concentrations of desloratadine and 3-hydroxydesloratadine. A human mass balance study documented recovery of approximately $87 \%$ of the $\left[{ }^{14} \mathrm{C}\right]$ desloratadine dose, which was equally distributed in the urine and feces as metabolic products. Its use is approved in Europe in children $\geq 1$ year old.

The safety of desloratadine has been evaluated in children 2-12 years of age with allergic rhinitis or CU for 15 days in a randomized, double-blind, placebo-controlled trial [31] and in multicentre double-blind, randomized, placebo-controlled trials in patients $>12$ years of age with chronic idiopathic urticaria for 6 weeks $[32,33]$.

Caution in treating epileptic patients is needed, as four children $(7,5,14$, and 16 years old) affected by different types of epilepsy were reported as having recurrence of seizures after desloratadine treatment [34•].

\section{Ebastine (C32H39N02)}

Ebastine has a rapid onset of action, and it can be administered once daily, with or without food. Dose modifications are not needed in elderly patients or in those with renal or mild to moderate hepatic impairment. Ebastine is generally well tolerated, and clinical studies have shown that at usual therapeutic doses of 10 and $20 \mathrm{mg}$ once daily, it has no clinically relevant adverse effects on cognitive function, psychomotor performance, or cardiovascular function [35].

Ebastine is rapidly absorbed and undergoes first-pass metabolism after oral administration. It is almost completely converted to the active metabolite carebastine. After an oral dose of ebastine $10 \mathrm{mg}$, maximum plasma levels $(80-100 \mathrm{ng} / \mathrm{ml})$ of carebastine are observed within 2.6-4 hours. After a single oral dose of ebastine $20 \mathrm{mg}$, peak plasma levels of the metabolite carebastine (average $195 \mathrm{ng} / \mathrm{ml}$ ) are observed within 3-6 hours. The half-life of the metabolite is $15-19$ hours, and $66 \%$ of it is excreted in the urine.

Some studies of concomitant use of ebastine with ketoconazole or erythromycin showed QTc prolongation of only $10 \mathrm{~ms}$, compared with administration of ketoconazole or erythromycin alone. Concomitant use of ebastine and ketoconazole, itraconazole, erythromycin, clarithromycin, or josamycin is not recommended. In clinical trials, no interactions were observed with concomitant use of ebastine with theophylline, warfarin, cimetidine, diazepam, or alcohol.

Use of ebastine is approved in Europe in children $\geq 12$ years old. 
The safety of ebastine has been evaluated in patients 12-65 years of age with seasonal allergic rhinitis in randomized, double-blind, placebo-controlled trials [35-37].

\section{Fexofenadine (C32H39N04)}

Fexofenadine is the pharmacologically active metabolite of terfenadine. In children, fexofenadine is rapidly absorbed and reaches its maximum plasma concentration after 2.4 hours. It should be administered before meals and well away from the intake of orange juice or grapefruit juice, which could reduce the bioavailability of this drug. Fexofenadine has a half-life of about 18 hours and is minimally metabolized, and its clearance rate is about $14.4 \mathrm{ml} / \mathrm{min} / \mathrm{kg}$. Clinical studies have demonstrated the cardiovascular safety of fexofenadine and that it is well tolerated in children [19].

Its use is approved in Europe for children $\geq 6$ years of age.

The safety of fexofenadine has also been evaluated in children aged 2-5 years with allergic rhinitis in a multicenter, placebo-controlled trial $[38,39]$.

\section{Mizolastine (C24H25FN60)}

Mizolastine belongs to the heterogeneous group of benzimidazole derivatives (astemizole).

Mizolastine $10 \mathrm{mg}$ /day is generally well tolerated, with the most common adverse events being drowsiness (7\%), fatigue ( $2 \%)$, increased appetite (2\%), and dry mouth (2\%). In volunteers and patients, the incidence of QTc interval prolongation was similar in mizolastine and placebo recipients, although mizolastine is contraindicated in those with cardiac disease or hepatic impairment, and in those receiving erythromycin, ketoconazole, or class I or III antiarrhythmic agents.

Mizolastine is approved in Europe for use in children $\geq 12$ years of age [40].

\section{Rupatadine (C26H26CIN3)}

Rupatadine is a non-sedating antihistamine with a rapid onset of action and a good safety profile.

In vitro studies have shown that it is metabolized in the liver by CYP enzymes. The most commonly reported adverse reactions are somnolence $(8.4 \%)$, headache $(1.7 \%)$, and diarrhea $(0.8 \%)$ [41]; other studies have reported the following most common adverse effects at the dose of $10 \mathrm{mg}$ once daily: headache $(7.6 \%)$, somnolence $(17.7 \%)$, asthenia (1.3\%), dizziness (3.8\%), and abdominal pain (3.7\%) [42]. Use of rupatadine is approved in Europe in children $\geq 12$ years of age [41].

The safety of rupatadine has been evaluated in randomized, double-blind, placebo-controlled studies in patients 12-65 years of age with chronic idi- 
opathic urticaria and in children 6-11 years of age with persistent allergic rhinitis [42-44].

\section{Alternative/adjunctive therapeutic options}

In both adults and children, CU very often persists for a long period, and if therapy with only H1-antihistamines doesn't work, it is possible to modify the treatment as suggested by the EAACI/GA ${ }^{2} \mathrm{LEN} / \mathrm{EDF} / \mathrm{WAO}$ guidelines (please note that this approach has not yet been validated for use in children) [15]:

- The drug dose can be increased to up to four times the recommended dose, with weight adjustment [45-47].

- A higher than standard dose of a non-sedating H1-antihistamine can be combined with a leukotriene antagonist and/or an H2-antihistamine.

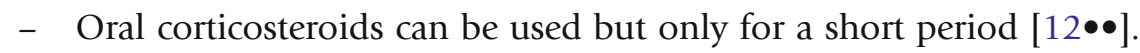

- Alternative therapeutic approaches, such as cyclosporine A, dapsone, or omalizumab, should be reserved for difficult cases in specialized centers.

Cyclosporine has a moderate, direct effect on mast cell mediator release, and it inhibits histamine release from basophil cells. Its use is recommended only for patients with severe disease that is refractory to an incremented dose of antihistamine. However, cyclosporine has a far better risk/benefit ratio than corticosteroids [15].

Montelukast is a leukotriene-receptor antagonist approved for pediatric use,

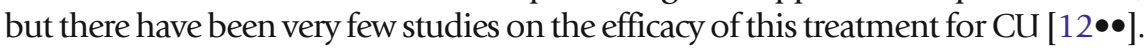

Phototherapy has been successfully used in treatment-resistant patients with $\mathrm{CU}$, as it reduces the number of mast cells in the upper dermis [15].

Omalizumab is an anti-IgE recombinant humanized monoclonal antibody, which reduces the levels of free IgE and mast cells and basophil activation. Its use has been approved for the treatment of moderate-to-severe persistent allergic asthma but not for CU. However, a phase 3, multicenter, randomized, double-blind study conducted in an adult population demonstrated that it diminished clinical symptoms and signs of CU: omalizumab was administered in three subcutaneous injections, spaced 4 weeks apart, at doses of 75,150 , and $300 \mathrm{mg}$, and the frequency of serious adverse events was low [48].

Although omalizumab has not yet been approved for the treatment of CU in children, there is some evidence, reported in the literature, that demonstrates the efficacy of omalizumab for the treatment of IgE-mediated diseases, such as CU, in children [49].

\section{Pediatric recommendations}

Studies of the efficacy and long-term safety of most antihistamines in children have been lacking up to now. However, there are many recommenda- 

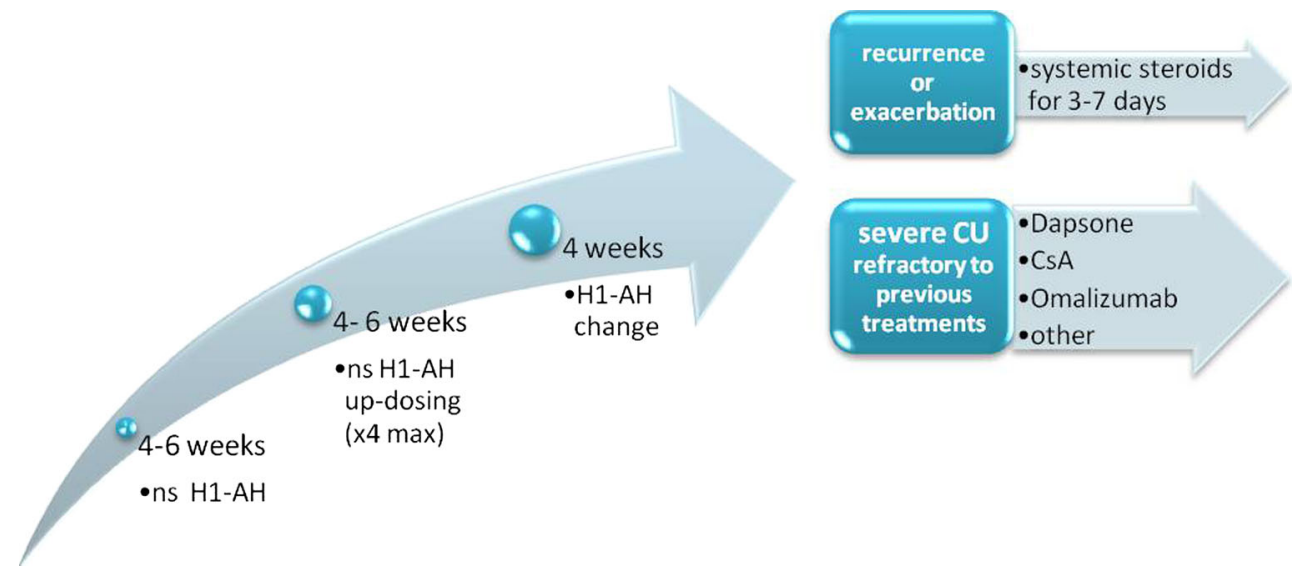

Fig. 1. Therapeutic algorithm for chronic urticaria (CU) in children, based on the literature and our experience. CsA: cyclosporine A. max: maximum. ns $\mathrm{H} 1-\mathrm{AH}$ : non-sedating $\mathrm{H} 1$-antihistamines.

tions for each type of antihistamine, which should be followed by physicians (listed in Table 1).

\section{What we do (our personal approach)}

On the basis of the literature $[2 \bullet \bullet, 3,4 \bullet \bullet, 5,6 \bullet \bullet, 12 \bullet \bullet, 15,16 \bullet \bullet, 19$, 20] and our personal experience, our first approach to the pharmacological treatment of CU in children is the use of second-generation (newgeneration) H1-antihistamines, with dose adjustment for pediatric use. If this approach doesn't work within 4-6 weeks, we simply increase the dose for another 4-6 weeks. However, while in adults the guidelines suggest an increase to four times the recommended dose, this approach is not yet validated in children. If the symptoms persist, we switch to a different second-generation $\mathrm{H} 1$-antihistamine for 4 weeks. In unresponsive patients, after re-evaluation of the case, or if there is an exacerbation, we suggest use of oral corticosteroids for 3-7 days. Only in the remaining very few patients with severe $\mathrm{CU}$ refractory to all of the previous treatments do we evaluate other drugs (cyclosporine A, dapsone, or omalizumab) (see Fig. 1).

\section{Compliance with Ethics Guidelines}

\section{Conflict of Interest}

Anna Belloni Fortina declares that she has no conflict of interest.

Elena Fontana declares that she has no conflict of interest.

Human and Animal Rights and Informed Consent

This article does not contain any studies with human or animal subjects performed by any of the authors. 


\section{References and Recommended Reading}

Papers of particular interest, published recently, have been highlighted as:

- Of importance

•- Of major importance

1. Zuberbier T, Asero R, Bindslev-Jensen C, Canonica GW, Church MK, Gimenez-Arnau A, et al. EAACI/ $\mathrm{GA}^{2} \mathrm{LEN} / \mathrm{EDF} / \mathrm{WAO}$ guideline: definition, classification and diagnosis of urticaria. Allergy. 2009;64:1417-26.

2.• Tsakok T, Du Toit G, Flohr C. Pediatric urticaria. Immunol Allergy Clin N Am. 2014;34:117-39.

An overview of urticaria management in children, based on a systematic online literature search.

3. Marrouche N, Grattan C. Childhood urticaria. Curr Opin Allergy Clin Immunol. 2012;12:485-90.

4.• Church MK, Weller K, Stock P, Maurer M. Chronic spontaneous urticaria in children: itching for insight. Pediatr Allergy Immunol. 2011;22:1-8.

An overview of chronic spontaneous urticaria in children, its underlying causes, comorbidities, and course, and the greater safety of second-generation antihistamines in children.

5. Caffarelli C, Cardinale F, Paravati F, Agnelli R, Barberi S, Belloni Fortina A, et al. Orticaria cronica in età pediatrica. Area Pediatr. 2010;11:5-26.

6.• Zitelli KB, Cordoro KM. Evidence-based evaluation and management of chronic urticaria in children. Pediatr Dermatol. 2011;28:629-39.

An overview of chronic urticaria in children, with an evidence-based approach.

7. $\quad$ Bruske I, Standl M, Weidinger S, Klumper C, Hoffmann B, Schaaf B, et al. Epidemiology of urticaria in infants and young children in Germany-results from the German LISAplus and GINIplus birth cohort studies. Pediatr Allergy Immunol. 2014;25:36-42.

One of the very few papers on the epidemiology of urticaria in children.

8. Khakoo G, Sofianou-Katsoulis A, Perkin MR, Lack G. Clinical features and natural history of physical urticaria in children. Pediatr Allergy Immunol. 2008;19:363-6.

9. Hiragun M, Hiragun T, Mihara S, Akita T, Tanaka J, Hide M. Prognosis of chronic spontaneous urticaria in 117 patients not controlled by a standard dose of antihistamine. Allergy. 2013;68:229-35.

10. Sahiner UM, Civelek E, Tuncer A, Tolga Yavuz S, Karabulut E, Sackesen C, et al. Chronic urticaria: etiology and natural course in children. Int Arch Allergy Immunol. 2011;156:224-30.

11. Caffarelli C, Cuomo B, Cardinale F, Barberi S, Povesi Dascola C, Agostinis F, et al. Aetiological factors associated with chronic urticaria in children: a systematic review. Acta Derm Venereol. 2013;93:268-72.

12.• Pite H, Wedi B, Borrego LM, Kapp A, Raap U. Management of childhood urticaria: current knowledge and practical recommendations. Acta Derm Venereol. 2013;93:500-8.

An updated and accurate review of the pharmacological and non-pharmacological management of childhood urticaria.

13. Longo G, Berti I, Burks AW, Krauss B, Barbi E. IgEmediated food allergy in children. Lancet. 2013;382:1656-64.

14. Akelma AZ, Cizmeci MN, Mete E, Tufan N, Bozkurt B. A neglected cause for chronic spontaneous urticaria in children: Helicobacter pylori. Allergol Immunopathol (Madr). 2014 (in press). doi:10.10167j.aller.2013.12.001.

15. Zuberbier T, Asero R, Bindslev-Jensen C, Canonica GW, Church MK, Gimenez-Arnau AM, et al. EAACI/ GA ${ }^{2}$ LEN/EDF/WAO guideline: management of urticaria. Allergy. 2009;64:1427-43.

16.• Simons FER, Simons KJ. Histamine and H1-antihistamines: celebrating a century of progress. J Allergy Clin Immunol. 2011;128:1139-50.

An excellent overview of the clinical pharmacology of H1antihistamines, both first-generation and second-generation.

17.• Church MK, Church DS. Pharmacology of antihistamines. Indian J Dermatol. 2013;58:219-24.

A recent review of the pharmacology of H1-antihistamines as the mainstay of treatment for urticaria, discussing the speed of onset, duration of action, elimination, and unwanted effects.

18. Criado PR, Criado RFJ, Maruta CW, Machado Filho CA. Histamine, histamine receptors and antihistamines: new concepts. An Bras Dermatol. 2010;85:195-210.

19. De Benedictis FM, de Benedictis D, Canonica GW. New oral $\mathrm{H} 1$ antihistamines in children: facts and unmeet needs. Allergy. 2008;63:1395-404.

20. Church MK, Maurer M, Simons FER, Bindslev-Jensen C, van Cauwenberge P, Bousquet J, et al. Risk of firstgeneration H1-antihistamines: a GA ${ }^{2} L E N$ position paper. Allergy. 2010;65:459-66.

21. Wolthers OD. Bilastine: a new nonsedating oral H1 antihitsamine for treatment of allergic rhinoconjunctivitis and urticaria. BioMed Res Int. 2013;2013:626837.

22. Simons FER, on behalf of the Early Treatment of the Atopic Child (ETAC) Study Group. Prevention of 
acute urticaria in young children with atopic dermatitis. J Allergy Clin Immunol. 2001;107:703-6.

23. Simons FER, Silas P, Portnoy JM, Catuogno J, Chapman D, Olufade AO. Safety of cetirizine in infants 6 to 11 months of age: a randomized, doubleblind, placebo-controlled study. J Allergy Clin Immunol. 2003;111:1244-8.

24. Singh-Franco D, Ghin HL, Robles GI, Borja-Hart N, Perez A. Levocetirizine for the treatment of allergic rhinitis and chronic idiopathic urticaria in adults and children. Clin Ther. 2009;31:1664-87.

25. Pampura AN, Papadopoulos NG, Spicak V, Kurzawa R. Evidence for clinical safety, efficacy, and parent and physician perceptions of levocetirizine for the treatment of children with allergic disease. Int Arch Allergy Immunol. 2011;155:367-78.

26. Simons FER, on behalf of the Early Prevention of Asthma in Atopic children (EPAAC) Study Group. Safety of levocetirizine treatment in young atopic children: an 18-month study. Pediatr Allergy Immunol. 2007;18:535-42.

27. Hampel F, Ratner P, Haeusler JMC. Safety and tolerability of levocetirizine dihydrochloride in infants and children with allergic rhinitis or chronic urticaria. Allergy Asthma Proc. 2010;31:290-5.

28. Monroe EW. Loratadine in the treatment of urticaria. Clin Ther. 1997;19:232-42.

29. Kay GG, Harris AG. Loratadine: a non sedating antihistamine. Review of its effects on cognition, psychomotor performance, mood and sedation. Clin Exp Allergy. 1999;29 Suppl 3:147-50.

30. Maimaiti G, Abduhaer A, Xu PR. Evaluation of efficacy and safety of loratadine in the treatment of childhood asthma. Zhongguo Dang Dai Er Ke Za Zhi. 2011;13:873-7.

31. Bloom M, Staudinger H, Herron J. Safety of desloratadine syrup in children. Curr Med Res Opin. 2004;20:1959-65.

32. Monroe E, Finn A, Patel P, Guerrero R, Ratner P, Bernstein D, et al. Efficacy and safety of desloratadine $5 \mathrm{mg}$ once daily in the treatment of chronic idiopathic urticaria: a double-blind, randomized, placebo-controlled trial. J Am Acad Dermatol. 2003;48:535-41.

33. Augustin M, Ehrle S. Safety and efficacy of desloratadine in chronic idiopathic urticaria in clinical practice: an observation study of 9246 patients. J Eur Acad Dermatol Venereol. 2009;23:292-9.

34. Cerminara C, El-Malhany N, Roberto D, Locastro A, Curatolo P. Seizures induced by desloratadine, a second-generation antihistamine: clinical observations. Neuropediatrics. 2013;44:222-4.

A short communication that calls attention to the possible risks of second-generation non-sedating antihistamines in epileptic children.
35. Sastre J. Ebastine in allergic rhinitis and chronic idiopathic urticaria. Allergy. 2008;63 Suppl 89:1-20.

36. Guadano EM, Serra-Batiles J, Meseguer J, Castillo JA, de Molina M, Valero A, et al. Rupatadine $10 \mathrm{mg}$ and ebastine $10 \mathrm{mg}$ in seasonal allergic rhinitis: a comparison study. Allergy. 2004;59:766-71.

37. Ratner P, Hampel F, Van Bavel J, Howland W. Efficacy and safety of ebastine $20 \mathrm{mg}$ compared to loratadine $10 \mathrm{mg}$ once daily in the treatment of seasonal allergic rhinitis: a randomized, doubleblind, placebo-controlled study. Int Arch Allergy Immunol. 2004;133:371-9.

38. Axelrod D, Bielory L. Fexofenadine hydrochloride in the treatment of allergic disease: a review. J Asthma Allergy. 2008;1:19-29.

39. Milgrom H, Kittner B, Lanier R, Hampel FC. Safety and tolerability of fexofenadine for the treatment of allergic rhinitis in children 2 to 5 years old. Ann Allergy Asthma Immunol. 2007;99:358-63.

40. Prakash A, Lamb HM. Mizolastine: a review of its use in allergic rhinitis and chronic idiopathic urticaria. BioDrugs. 1998;10:41-63.

41. Lukat $\mathrm{KF}$, Rivas $\mathrm{P}$, Roger $\mathrm{A}$, Kowalski ML, Botzen U, Wessel F, et al. A direct comparison of efficacy between desloratadine and rupatadine in seasonal allergic rhinoconjunctivitis: a randomized, doubleblind, placebo-controlled study. J Asthma Allergy. 2013;6:31-9.

42. Church MK, Maspero JF, Maurer M, Ryan D. The scope of pharmacological and clinical effects of modern antihistamines with a special focus on rupatadine: proceedings from a satellite symposium held at the 21st World Allergy Congress, Buenos Aires, December 8, 2009. World Allergy Organ J. 2010;3(4 Suppl):S1-S16.

43. Gimenez-Arnau A, Pujol RM, Ianosi S, Kaszuba A, Malbran A, Poop G, et al. Rupatadine in the treatment of chronic idiopathic urticaria: a double-blind, randomized, placebo-controlled multicentre study. Allergy. 2007;62:539-46.

44. Potter P, Maspero JF, Vermeulen J, Barkai L, Nemeth I, Baillieau RA, et al. Rupatadine oral solution in children with persistent allergic rhinitis: a randomized, double-blind, placebo-controlled study. Pediatr Allergy Immunol. 2013;24:144-50.

45. Zuberbier T. Pharmacological rationale for the treatment of chronic urticaria with second-generation non-sedating antihistamines at higher-thanstandard doses. J Eur Acad Dermatol Venereol. 2012;26:9-18.

46. Sanchez-Borges M, Caballero-Fonseca F, CaprilesHulett A. Treatment of recalcitrant chronic urticaria with nonsedating antihistamines: is there evidence for updosing? J Investig Allergol Clin Immunol. 2013;23:141-4. 
47. Silva D, Ansotegui I, Morais-Almeida M. Off-label prescribing for allergic diseases in children. World Allergy Organ J. 2014;7:4.

48. Maurer M, Rosen K, Hsieh HJ, Saini S, Grattan C, Gimenez-Arnau A, et al. Omalizumab for the treat- ment of chronic idiopathic or spontaneous urticaria. N Engl J Med. 2013;368:924-35.

49. Baena-Cagnani CE, Gomez RM. Current status of therapy with omalizumab in children. Curr Opin Allergy Clin Immunol. 2014;14:149-54. 